\title{
Concurrence of multiple sclerosis and glioma
}

\author{
S. CURRIE ${ }^{1}$ AND H. URICH \\ From the Departments of Neurology and Neuropathology, \\ Section of Neurological Sciences, The London Hospital, London
}

SYNOPSIS Three cases are reported of concurrence of malignant gliomas (astrocytomas and glioblastomas) with multiple sclerosis (MS). This situation may lead to considerable diagnostic difficulties, yet an accurate appraisal is of prognostic, if not therapeutic, value. There is suggestive but inconclusive evidence that the two conditions may be causally related, malignant astrocytic tumours arising from plaques of MS. The small number of reported cases makes statistical analysis impossible, but the scanty literature may not reflect the true incidence.

The concurrence of multiple sclerosis (MS) and cerebral glioma appears to be rare. Only 12 cases have been described (Table) in reports which were wholly or mainly concerned with the pathological findings. In six cases there was a pre-existing neurological disorder due to MS before the onset of that due to tumour (MunchPeterson, 1949; Matthews, 1962; Barnard and Jellinek, 1967; Boyazis et al., 1967; Aubert et al., 1968; Mathews and Moossy, 1972); in the case 1 Present address-St. James's (University) Hospital, Leeds, 9. described by Mathews and Moossy there was peroneal muscular atrophy as well. In the other six cases no clinical diagnosis of MS was made, plaques of demyelination being an unexpected finding at necropsy (Scherer, 1938; Zimmerman and Netsky, 1950; Brihaye et al., 1963; Russell and Rubinstein, 1971). Contiguity between tumour and plaques was noted in five cases andô multifocal tumours were found in three, being generalized gliomatosis in one. In this, the first case to be reported (Scherer, 1938), there

TABLE

MULTIPLE SCLEROSIS AND GLIOMA

\begin{tabular}{|c|c|c|c|c|c|}
\hline Case report* & $\begin{array}{c}\text { Sex; age } \\
\text { when tumour } \\
(y r)\end{array}$ & $\begin{array}{c}\text { Antecedent } \\
\text { history of } \\
M S\end{array}$ & Tumour cell type & $\begin{array}{l}\text { Contiguity of } \\
\text { plaques and } \\
\text { tumour }\end{array}$ & $\begin{array}{l}\text { Multiple } \\
\text { tumours }\end{array}$ \\
\hline 1. Scherer (1938) & F 29 & - & Gliomatosis & + & + \\
\hline 2. M. Petersen (1949) & F 49 & + & Glioblastoma & - & - \\
\hline 3. Zimmerman and Netsky (1950) & $?$ ? & - & Glioblastoma & $?$ & - \\
\hline 4. Matthews (1962) & F 51 & + & Astrocytoma & $?$ & - \\
\hline 5. Brihaye et al. (1963) & M 62 & - & Astrocytoma & + & - \\
\hline 6. Barnard and Jellinek (1967) & F 43 & + & Oligodendroglioma & - & - \\
\hline 7. Boyazis et al. (1967) & F 54 & + & Glioblastoma & - & - \\
\hline 8. Aubert et al. (1968) & F 50 & + & Glioblastoma & - & - \\
\hline 9. Russell and Rubinstein (1971) 1 & F 36 & - & $\begin{array}{l}\text { Astrocytoma and } \\
\text { glioblastoma }\end{array}$ & + & + \\
\hline 10. Russell and Rubinstein (1971) 2 & M 66 & - & $\begin{array}{l}\text { Subependymoma and } \\
\text { glioblastoma }\end{array}$ & + & + \\
\hline 11. Russell and Rubinstein (1971) 3 & M Middle-aged & - & Astrocytoma & + & - \\
\hline $\begin{array}{l}\text { 12. Mathews and Moossy (1972) } \\
\text { Present paper }\end{array}$ & M 44 & + & Mixed glioma & - & - \\
\hline 13. Case 1 & F 37 & + & Glioblastoma & - & - \\
\hline 14. Case 2 & M 63 & + & $\begin{array}{l}\text { Astrocytoma and } \\
\text { glioblastoma }\end{array}$ & + & + \\
\hline 15. Case 3 & M 53 & + & Glioblastoma & + & - \\
\hline
\end{tabular}

* cf references. 
appeared to be a transition from the macroglial proliferation of plaques to frank neoplasia. Subsequent authors have followed this lead in postulating a causal relationship between the two conditions.

We present three further cases, in each of which diagnostic problems arose in life from the syndrome due to tumour being superimposed on that due to MS. The pathological findings are comparable with those in the previously published cases.

\section{CASE 1}

(D.W., female, LH No. 304710/0) The patient first presented in March 1965 at the age of 35 years with a history of intermittent diplopia for five years and of leg clumsiness and slurred speech for months; in 1961 there had been frequency of micturition. The signs on examination were temporal pallor of the optic discs, 'ataxic' nystagmus on lateral gaze, dysarthria, spastic paraparesis, loss of vibration sense in the lower limbs, and ataxia of all four limbs. On admission in June 1966, examination of the cerebrospinal fluid showed a paretic Lange curve (443321) with negative serology; other investigations were normal. A course of adrenocorticotrophin (ACTH) and physiotherapy was given; there was no improvement. She returned to the hospital in April 1967 on account of drowsiness; this was ascribed to mephenesin, which was stopped. A further course of ACTH (40 i.u. daily) was commenced. However, on 9 May 1967 she was admitted with a history of drowsiness leading to coma over a period of days. She was comatose with bradycardia and shallow respiration. The fundal appearances were unaltered, with no venous engorgement. Her state was thought to be due to cerebral oedema assosiated with massive demyelination; the alternative possibility of tumour was considered. An echogram showed no midline shift. The daily dose of ACTH was raised to 80 i.u. Three days later she regained consciousness. A left homonymous hemianopia was present, as were total external ophthalmoplegia, rotatory nystagmus on central fixation, and ptosis, more marked on the right with a small pupil; there was also a left hemiplegia. During the next month her mental state fluctuated between relative clarity and marked drowsiness; there was no overall improvement except that of the first few days. Serial electroencephalograms showed diffuse delta wave activity and right-sided flattening of complexes. Eventually there was further sharp deterioration. A right frontal burrhole was made and gliomatous tissue obtained. The patient died shortly afterwards.

MACROSCOPIC APPEARANCES The brain was large and soft with expansion of the anterior half of the right hemisphere and flattening of convolutions in the right frontal and temporal lobes. On section a large tumour $(7.5 \times 4 \times 8 \mathrm{~cm})$ was found in the right hemisphere occupying the white matter of the frontal and anterior third of the temporal lobe, the head of the caudate nucleus, the putamen, globus pallidus, internal capsule, and thalamus (Fig. 1). It extended into the tectum of the mid-brain where it obstructed the aqueduct. The lateral and third ventricles were moderately dilated. The cut surface of the tumour was greyish, mottled with haemorrhages and yellow areas of necrosis. Demarcation from surrounding

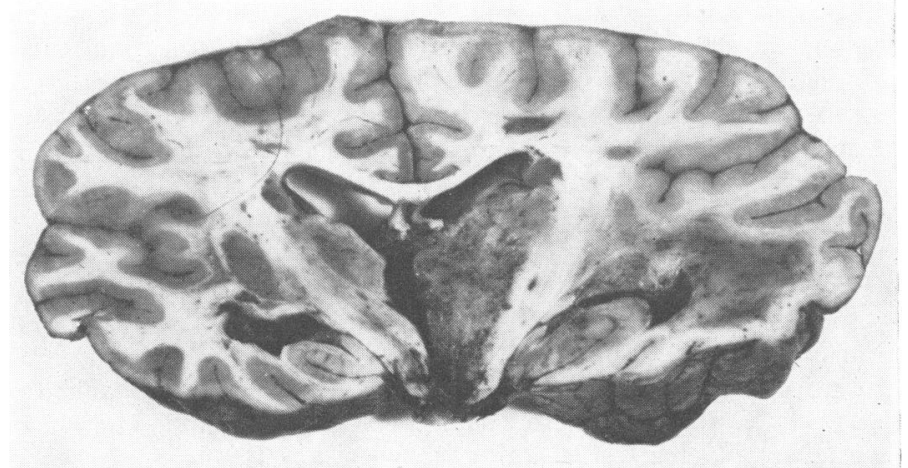

FIG. 1. Case 1. Coronal slice of brain showing tumour in right thalamus and temporal lobe, also scattered plaques of multiple sclerosis. 


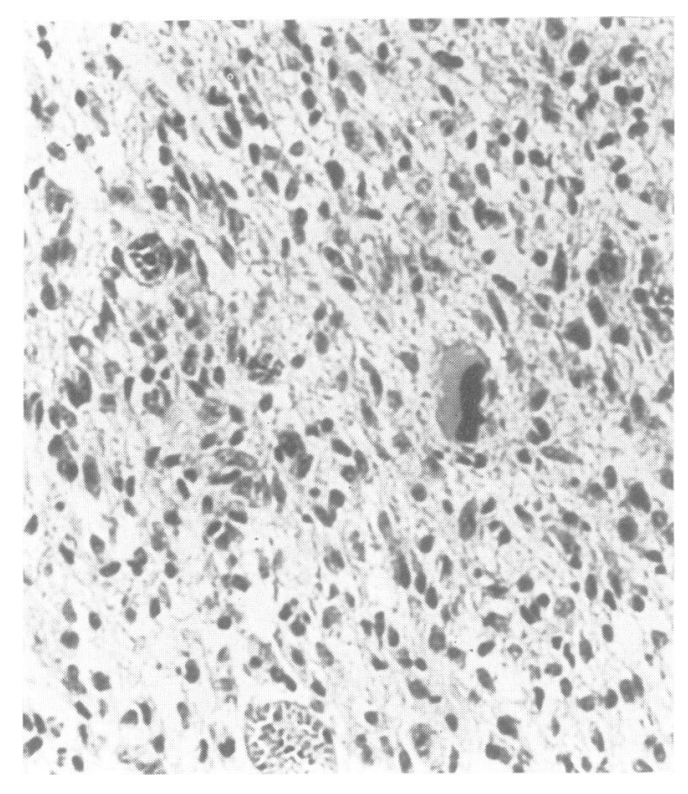

FIG. 2. Case 1. Tumour showing uniformly distributed, somewhat hyperchromatic, astrocytic nuclei with one bizarre giant cell. $H$ and $E, \times 260$.

brain tissue was indistinct. The frontal white matter adjacent to the tumour was oedematous.

Numerous well-defined, grey semi-translucent plaques of demyelination were found in both cerebral hemispheres. Most of them were paraventricular, situated at the lateral angles of the lateral ventricles. The largest lesions were found in the neighbourhood of the posterior horns, particularly the left. A thin zone of demyelination was present on the ventricular surface of the corpus callosum. Scattered plaques, unrelated to the ventricular surface, were also seen in the white matter of both frontal and occipital lobes and the left thalamus. In the brain-stem demyelination was confined to the pontine tegmentum. Both optic nerves showed almost total demyelination.

In the spinal cord small wedge-shaped plaques were seen in the lateral and posterior columns of the cervical and upper thoracic segments.

MICROSCOPY Tumour The appearances were those of a glioblastoma with some astrocytic differentiation. Some areas consisted of moderately large cells, polygonal or spindle-shaped, with oval vesicular nuclei varying considerably in size, and fairly clearly defined eosinophilic cytoplasm. Occasional large cells with bizarre, hyperchromatic nuclei were scattered through the tumour (Fig. 2). Scanty fine glial fibrils were present in this part of the tumour. Other areas consisted almost entirely of small cells with round, oval, or rod-shaped pyknotic nuclei, and indistinct cytoplasm, devoid of glial fibres. Thin-walled blood vessels of various sizes were abundant, many of them thrombosed. No endothelial or adventitial proliferation was seen. Numerous areas of necrosis with pseudo-palisading were present.

Plaques All plaques appeared to be old and inactive, with total loss of myelin and relative preservation of axons. Fibrillary gliosis of variable density was seen in all plaques. They were sparsely cellular and only scattered astrocytic nuclei could be seen. There was no evidence of microglial activity at the edges, but sparse perivascular lymphocytic infiltration was seen in places.

Relation of tumour to plaques No definite contiguity between the two types of lesion was seen in any of the sections examined.

\section{CASE 2}

(G.W.S., male: Bethnal Green H. No. 6529; Princ鸟 of Wales H. No. 121957; Whittington H. No. $312055 \Phi-$ At the age of 38 years in 1942, two days after a minos 3 head injury, this man developed a left hemiparesio which resolved over a month. In 1958 he presented. $\vec{\theta}$ with a two years' history of stiffness of the legs? numbness in the feet, with a sensation of walking on wool, and imbalance. On examination there was spasticity, loss of pain perception and vibration sense in the lower limbs, and disequilibrium. Lumbar puncture showed normal manometry, cell count, serology, and total protein but a mid-zone Lange curve (0123210000). Mobility improved with physiotherapy. During the next decade the condition fluctuated. Early in 1967 at the age of 62 years, the patient had several falls and showed sexual aggression and slurring of speech. Three days after one fall a right hemiparesis developed. On examination he also had a right homonymous hemianopia; the fundi were considered to be normal. There was incoordination in the upper limbs. Improvement occurred; a cerebrovascular event was thought likely. In October 1967 he was admitted to hospital after sudden collapse with loss of consciousness. He was confused and dysarthric. The left optic disc showed temporal pallor with blurring of the nasal margin as well; on the right there was marked papilloedema. There was defective lateral gaze with a possible sixth nerve palsy. The patient was transferred to a neurosurgical unit; burrholes were made, showing no subdural haematoma. The patient died on 10 October 1967. 


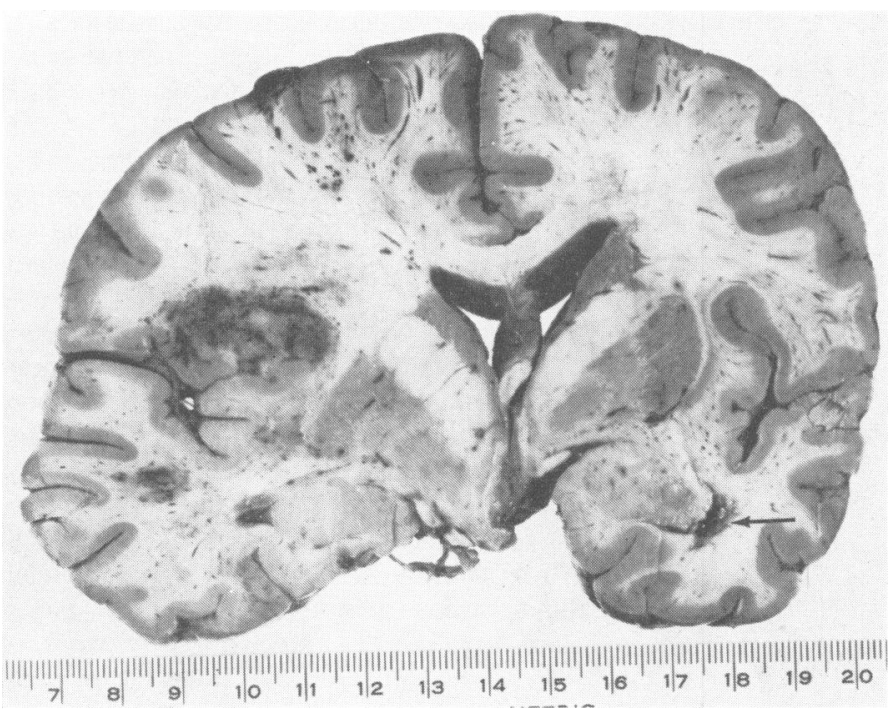

FIG. 3. Case 2. Coronal slice of brain with tumours in left frontal and temporal lobes and small plaque of demyelination in neighbourhood of right inferior horn (arrow).

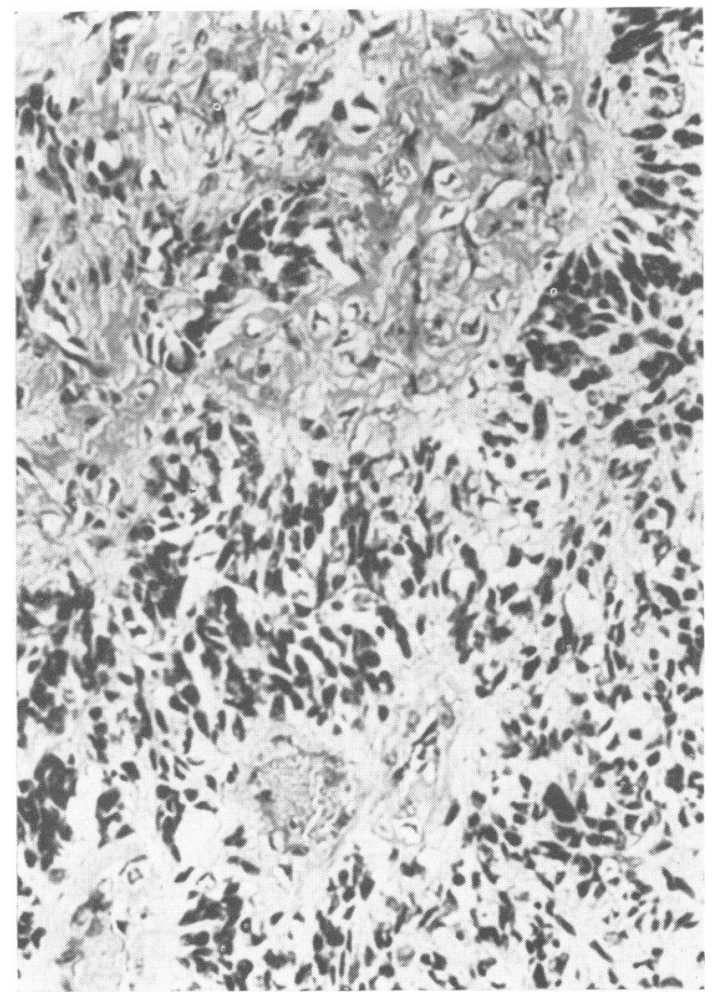

FIG. 4. Case 2. Anaplastic tumour in frontal lobe consisting of closely packed, hyperchromatic cells. $H$ and $E, \times 260$.
MACROSCOPIC APPEARANCES The brain was large and the left hemisphere obviously expanded. This was due to the presence of several, apparently unconnected, foci of tumour, each about $2-3 \mathrm{~cm}$ in diameter, scattered through the grey and white matter of the left hemisphere (Fig. 3). The main foci were in the white matter of the frontal lobe, the insula, the inferior temporal cortex, the cingulate gyrus and adjacent part of the splenium of the corpus callosum, the occipital white matter in the neighbourhood of the posterior horn of the lateral ventricle, and in the ventrolateral part of the thalamus with an extension into the tectum. These foci were mottled in appearance with haemorrhages and areas of necrosis and were poorly demarcated from the surrounding tissue. There was a slight shift of the mid-line structures to the right, with herniation of the cingulate gyrus under the falx. No obvious plaques of demyelination were seen in the left hemisphere.

In the right hemisphere small, greyish, irregular areas of demyelination were seen in the neighbourhood of the posterior horn of the lateral ventricle and in the right half of the splenium of the corpus callosum. In the brain-stem similar plaques were present in the pontine tegmentum, in the right middle cerebellar peduncle and in the left medullary pyramid.

The spinal cord was slender and flattened in the anteroposterior diameter. It showed some blurring of pattern and scattered well-defined plaques of demyelination in the cervical and thoracic segments. 


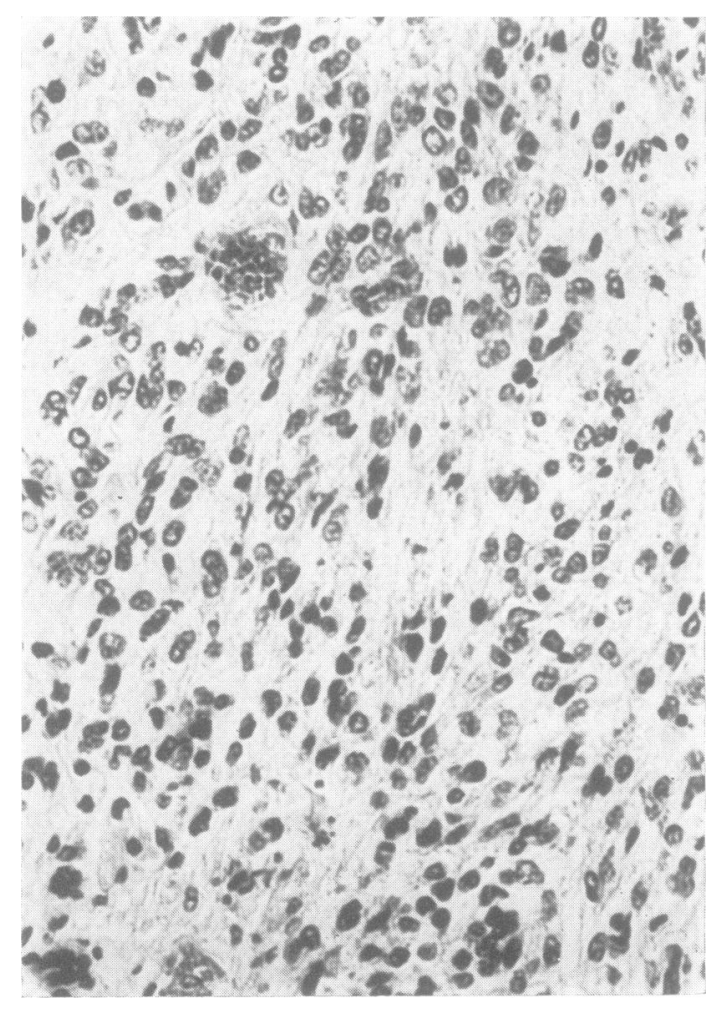

FIG. 5. Case 2. Tumour in corpus callosum with welldifferentiated astrocytic nuclei. $H$ and $E, \times 260$.

The lumbar cord was well preserved and the anterior and posterior roots normal.

MICROSCOPY Tumours All tumours were malignant astrocytomas showing minor variations in the degree of differentiation. The predominant pattern was that of a loosely woven, microcystic texture with abundant spindle-shaped and stellate cells, the processes of which contained sparse, stout, glial fibres. Their nuclei were pleomorphic, mainly elongated, with a dense chromatin pattern. More anaplastic areas were highly cellular, with somewhat larger, oval, hyperchromatic nuclei, and indistinct cytoplasm (Fig. 4). Occasional large bizarre cell forms were present. These areas were devoid of glial fibres. More highly differentiated tumour tissue of an obviously astrocytic pattern with oval, pale nuclei and numerous fine glial fibrils was found in the cingulate gyrus and corpus callosum (Fig. 5). No tumour cells were seen in the intervening tissue.

The tumours were highly vascular, but only a few vessels showed endothelial hyperplasia. Adventitial hyperplasia without concomitant malignant change in the connective tissue was prominent in some of the larger vessels. Extensive areas of necrosis were seen particularly in the anaplastic areas.

Plaques All the plaques in the right hemisphere, brain-stem, and spinal cord appeared old and inactive. They were completely devoid of myelin and oligodendroglial cells, and the astrocytes were relatively sparse with scanty stainable cytoplasm but abundant glial fibres. The edges of the plaques showed no accumulation of microglial cells. There was no lymphocytic cuffing of blood vessels. One plaque in the spinal cord, adjacent to the posterior root entry zone at T12 segment, was more highly cellular and contained shoals and whorls of spindlecells with long, darkly staining rod-shaped nuclei. These cellular areas contained numerous axons, some of them myelinated, and a dense network of reticulin fibres. The appearances suggested invasion of scar tissue by Schwann-cells from the adjacent nerve root.

Relation of tumour to plaques A small cortica plaque was found adjacent to one of the tumours? Two discrete small plaques were found in the lefto thalamus at some distance from the tumour mass from which they were separated by a zone of normal tissue.

\section{CASE 3}

(G.H.P., Newcastle Gen. H. No. N23245) In 1940 at the age of 26 years this man developed a spastic paraparesis which slowly progressed over the years; a diagnosis of MS was made. Subsequently a spinal cord compressive lesion was excluded by myelography. In 1963 he developed intellectual deterioration and progressive weakness of the upper limbs. During the course of the illness there had been episodes of diplopia, distal paraesthesiae, and frequency of micturition. He came to Newcastle General Hospital in May 1968, at the age of 54 years. The earlier diagnosis of MS was doubted and arrangements were made to admit him for myelography to exclude a lesion at the foramen magnum. However, shortly afterwards he was sent in with a history of headache, and drowsiness. There was papilloedema, more marked on the right side, also left hemianopia and hemiplegia in addition to the signs recorded earlier. Radiographs of the skull showed pineal displacement and right carotid arteriography a temporoparietal tumour with subdural haematoma. On craniotomy gliomatous tissue was obtained. The patient died three months later on 14 August 1968. 


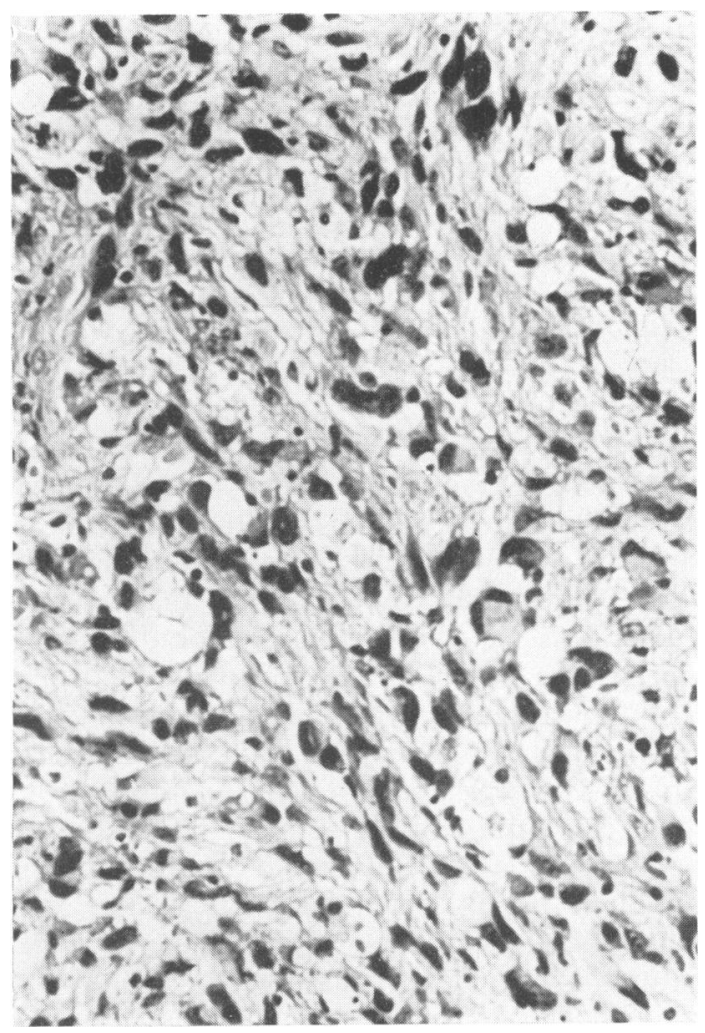

FIG. 6. Case 3. Large-celled glioblastoma with pleomorphic and hyperchromatic nuclei. $H$ and $E$, $\times 260$.

MACROSCOPICAL APPEARANCE (G.H.P., Chester-leStreet Gen. H. PM No. 289/67) (Only embedded blocks of tissue were available for re-examination and we are indebted to Dr. G. S. Graham for the following description.)

There was a fairly recent operation scar under which the dura mater and the brain were adherent and bulging; there was some haemorrhagic softening in the right temporal pole of the brain with a peasized indurated area which could have been residual tumour. The brain showed no other external abnormality but section revealed subependymal scars in the lateral and inferior walls of the lateral ventricles, the larger cutting into the brain tissue to a depth of almost $1 \mathrm{~cm}$ on the right side. Elsewhere, there were typical rounded plaques in white matter both of the hemispheres and cerebellum, involving the olivary nucleus on the left side. Some of these plaques, which measured up to $5 \mathrm{~mm}$ in diameter, showed central congested vessels. The cervical cord was normal.

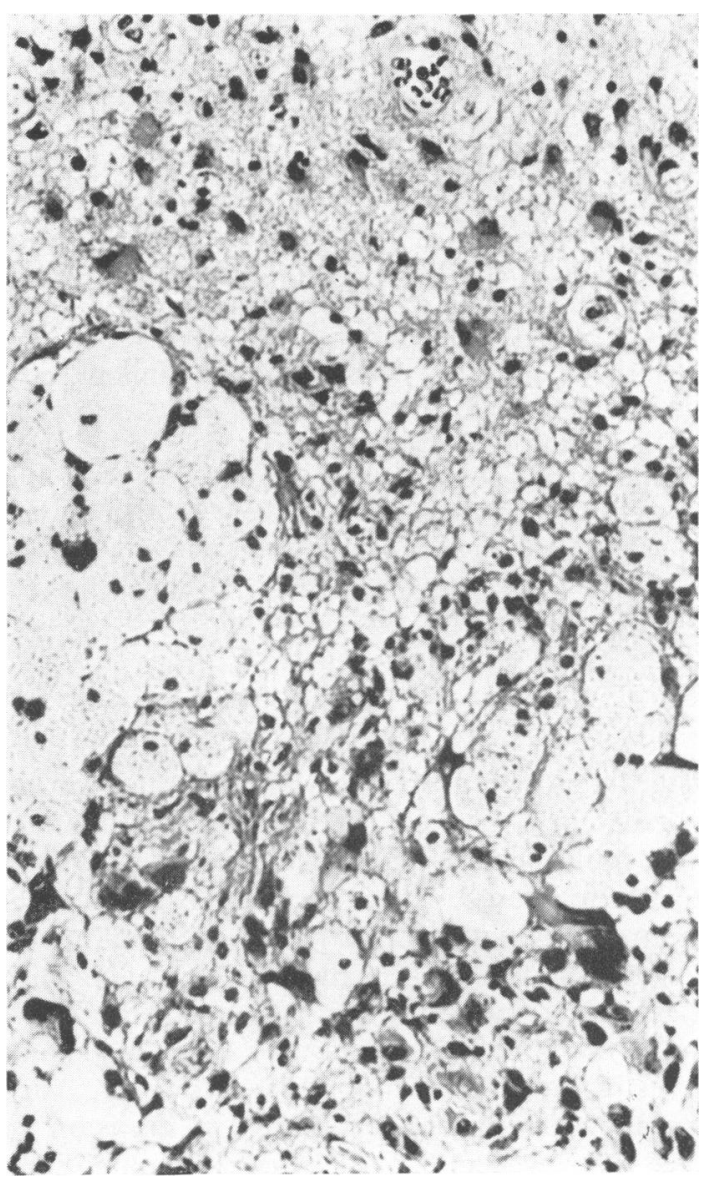

FIG. 7. Case 3. Contiguous plaque of demyelination and tumour: hyperplastic astrocytes at top, neoplastic cells at bottom, nests of lipid macrophages between. $H$ and $E, 260$.

MICROSCOPY (H. Urich) Tumour The appearances were those of a large-celled glioblastoma consisting of round, polygonal, or spindle-shaped cells, with abundant cytoplasm and large nuclei of various shapes with moderately dense chromatin. Many bizarre forms were present, some lobed, some ringshaped with a central eosinophilic inclusion (Fig. 6). The tumour was moderately vascular, some vessels showing marked adventitial hyperplasia. Areas of necrosis were scattered through the tumour. Several aggregates of lipid macrophages were present near the edge of the tumour. Intense perivascular lymphocytic infiltration was a striking feature.

Plaques Both old and recent plaques were present. In both there was total loss of myelin and oligo- 
dendroglial cells. While some showed only moderate astrocytic hyperplasia and little evidence of microglial activity, others showed abundant gemistocytic astrocytes, numerous lipid macrophages in the periphery and pronounced lymphocytic cuffing of blood vessels.

Relation of tumour to plaques There was contiguity and in places overlapping of the two types of lesion (Fig. 7). Some of the recent plaques were seen in the vicinity of tumour, with anaplastic tumour cells intermingling with hypertrophic reactive astrocytes of the plaques. No intermediate cell forms were observed. The islands of fat granule cells described above were found in areas adjacent to plaques and may have been derived from them and engulfed by the tumour. No significant difference could be seen between the lymphocytic infiltration of the plaque and the tumour.

\section{DISCUSSION}

The diagnostic problems which result from an intracerebral tumour developing in a patient with multiple sclerosis may be of no more than academic interest. The association is so rare that in an individual case the possibility may not be considered. Even if it is, then the lack of effective therapeutic measures for either disorder may make the clinician reluctant to carry out major investigations entailing risks. However, such therapeutic nihilism will lead on occasion to treatable coincidental lesions remaining undiagnosed, such as subdural haematoma. The habit of unitary diagnosis dies hard, though coincidence with other disorders is to be expected in a common condition with a protracted course. In each of the three cases described here the sequence of tumour occurring in the context of longstanding MS went unrecognized. In case 1 , the possibility of tumour was raised on the last admission. However, an expectant policy was adopted in a desire to ascribe the fresh developments to the established diagnosis of MS and to avoid exacerbating this by investigation. A carotid arteriogram carried out shortly after admission would have been both safe and opportune. In case 3 when deterioration occurred due to the tumour the diagnosis of MS was doubted and a compressive lesion at the foramen magnum was considered.

Clinical assessment in at least one of these cases was hampered by the presence of optic atrophy. This was case 1 , in whom it was sufficient in degree to prevent oedema of the optic discs and retina, despite marked intracranial hypertension. In case 2, optic atrophy was appreciable only on the left side and only as temporal pallor of the disc. This restricted oedema to blurring of the nasal margin of the disc, while on the right side, contralateral to the tumour, there was gross papilloedema by the time of the final admission. Behrman (1966), in his review of the mechanisms of papilloedema, holds that the glial sclerosis of optic atrophy makes the disc compact, preventing oedema. Presumably, it also stops the blush of capillary proliferation on the nerve head which is characteristic of papilloedema and which is best shown by fluorescein angiography. Such gliosis may be responsible for the fundal appearances in the Foster Kennedy syndrome of optic atrophy on the side of a retro-orbital tumour with contralateral papilloedema. This explanation is preferable to that of "protection ' of the disc from engorgement by obliteration of in the perineurial subarachnoid space by the $\infty$ tumour as papilloedema can occur despite suclp 음 obliteration (Behrman, 1966). Other clinica $\bar{P}-$ features in the present cases were less liable to give difficulty. In neither case 1 nor case 3 was the coma typical of that which may occur in MS due to plaques near the third ventricle; such coma is characteristically rapid in onset, deep, accompanied by hyperpyrexia, and recurrent (Castaigne et al., 1966). The transient response to steroid therapy in case 1 might have occurred in either MS or tumour.

The occasional development of gliomas in cases of multiple sclerosis is now an established fact, but the number of reported cases is still small. Whether the paucity of data reflects the true incidence of neoplasia in MS is uncertain. Postmortem examinations are carried out on only a small number of patients with MS. In the absence of statistical evidence the case for a relationship rests on pathological observations in individual instances. The crucial demonstration that tumours have originated from plaques is rarely possible. Most tumours reach a considerable size by the time of the patient's death and may have obliterated the plaques from which they have arisen and also may have encroached upon other plaques. Tumours contiguous with plaques may, therefore, represent collision lesions. The 
first case of Russell and Rubinstein (1971) is important as the brain contained a minute glioblastoma, $0.4 \mathrm{~cm}$ in diameter, clearly associated with a plaque.

Equally slender evidence of a causal relationship comes from arguments based on cell type. Most of the recorded gliomas in multiple sclerosis are malignant astrocytomas or glioblastomas in which the degree of anaplasia has resulted in cells dissimilar from the hyperplastic astrocytes of plaques. As these tumours represent the common gliomas of adult life, it may be argued that they would predominate anyway even if the association were fortuitous. If the gliomas do originate in the hyperplastic elements of the demyelinating lesions they should belong to the astrocytic series. It is of interest that in the third case of Russell and Rubinstein the tumour cells of a gemistocytic astrocytoma closely resembled the astrocytes of the plaques. Other tumours have been recorded only in single instances. These include a subependymoma (Russell and Rubinstein, case 2), a doubtful ependymoma (MunchPetersen, 1949, reinterpreted as glioblastoma by Russell and Rubinstein), and oligodendroglioma (Barnard and Jellinek, 1967), and a mixed astrocytoma-oligodendroglioma (Mathews and Moossy, 1972). If the contention of Ibrahim and Adams $(1963,1965)$ that there is an early oligodendroglial proliferation in plaques is correct then more oligodendrogliomas should develop. Their views, however, have received little support from other workers (Lumsden, 1970). A final point which hints at a causal relationship is the relatively high frequency of multiple tumours when glioma occurs with MS. This exceeds even the exceptionally high estimate of $20 \%$ which Scherer (1940) gave as the frequency of multiple tumours in all cases of glioma.

We wish to thank the physicians and surgeons under whose care the patients had been and who allowed us access to case notes; we also thank the pathologists who have provided both specimens and details of postmortem findings.

\section{REFERENCES}

Aubert, L., Arroyo, H., Daumas, B., and Tripier, M. F. (1968). Un cas d'association entre sclérose en plaques et glioblastome cérébral. Revue Neurologique, 119, 374-376.

Barnard, R. O., and Jellinek, E. H. (1967). Multiple sclerosis with amyotrophy complicated by oligodendroglioma. History of recurrent herpes zoster. Journal of Neurological Sciences, 5, 441-455.

Behrman, S. (1966). Pathology of papilloedema. Brain, 89, 1-14.

Boyazis, R. M., Martin, L., Bouteille, M., Guazzi, G. C., and Manacorda, A. (1967). Images histochimiques et ultrastructurales dans un cas de sclérose en plaques associée à un spongioblastome. Rivista di Patologia Nervosa e Mentale, 88, 1-20.

Brihaye, J., Perier, O., and Sténuit, J. (1963). Multiple sclerosis associated with a cerebral glioma. Journal of Neuropathology and Experimental Neurology, 22, 128-137.

Castaigne, P., Escourolle, R., Laplane, D., and Augustin, P. (1966). Comas transitoires avec hyperthermie au cours de la sclérose en plaques. Encéphale, 55, 191-211.

Ibrahim, M. Z. M., and Adams, C. W. M. (1963). The relationship between enzyme activity and neuroglia in plaques of multiple sclerosis. Journal of Neurology, Neurosurgery, and Psychiatry, 26, 101-110.

Ibrahim, M. Z. M., and Adams, C. W. M. (1965). The relation between enzyme activity and neuroglia in early plaques of multiple sclerosis. Journal of Pathology and Bacteriology, 90, 239-243.

Lumsden, C. E. (1970). The neuropathology of multiple sclerosis. In Handbook of Clinical Neurology, Vol. 9, pp. 217-309. Edited by P. J. Vinken and G. W. Bruyn. North Holland: Amsterdam.

Mathews, T., and Moossy, J. (1972). Mixed glioma, multiple sclerosis, and Charcot-Marie-Tooth disease. Archives of Neurology, 27, 263-268.

Matthews, W. B. (1962). Epilepsy and disseminated sclerosis. Quarterly Journal of Medicine, 31, 141-155.

Munch-Petersen, C. J. (1949). A case of disseminated sclerosis and glioma of the brain in the same patient. Acta Psychiatrica et Neurologica, 24, 599-605.

Russell, D. S., and Rubinstein, L. J. (1971). Pathology of Tumours of the Nervous System, 3rd edn., p. 179. Arnold: London.

Scherer, H. J. (1938). La 'glioblastomatose en plaques': sur les limites anatomiques de la gliomatose et des processes sclérotiques progressifs (sclérose en plaques, sclérose diffuse de Schilder, sclérose concentrique). Journal Belge de Neurologie et de Psychiatrie, 38, 1-17.

Scherer, H. J. (1940). The forms of growth in gliomas and their pathological significance. Brain, 63, 1-35.

Zimmerman, H. M., and Netsky, M. G. (1950). The pathology of multiple sclerosis. Research Publications, Association for Research in Nervous and Mental Disease, 28, 271-312. 